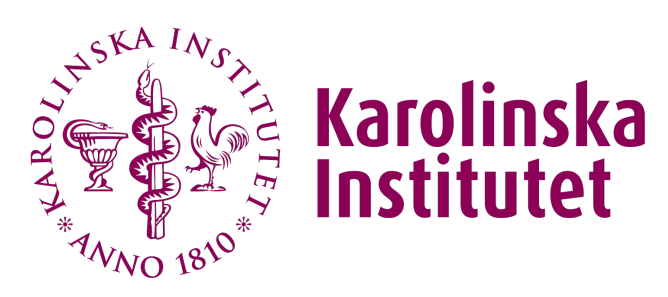

Karolinska Institutet

http://openarchive.ki.se

This is a Peer Reviewed Accepted version of the following article, accepted for publication in Pediatric allergy and immunology.

2017-01-16

\title{
The influence of childhood asthma on puberty and height in Swedish adolescents
}

Protudjer, Jennifer; Lundholm, Cecilia; Bergström, Anna; Kull, Inger; Almqvist, Catarina

Pediatr Allergy Immunol. 2015 Aug;26(5):474-81.

http://doi.org/10.1111/pai.12398

http://hdl.handle.net/10616/45494

If not otherwise stated by the Publisher's Terms and conditions, the manuscript is deposited under the terms of the Creative Commons Attribution-NonCommercial-NoDerivatives License (http://creativecommons.org/licenses/by-nc-nd/4.0/), which permits non-commercial re-use, distribution, and reproduction in any medium, provided the original work is properly cited, and is not altered, transformed, or built upon in any way. 


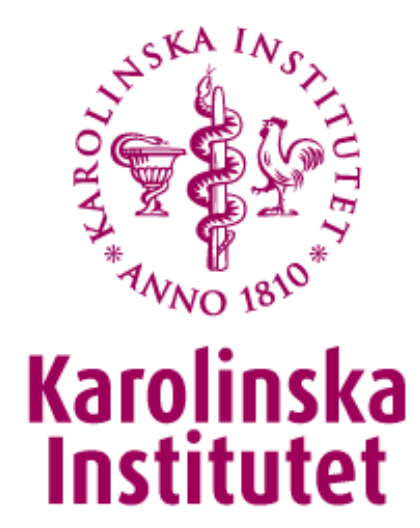

This is the peer reviewed version of the following article Pediatr Allergy Immunol. 2015 Aug;26(5):474-81., which has been published in final form at

http://dx.doi.org/10.1111/pai.12398

This article may be used for non-commercial purposes in accordance with Wiley Terms and Conditions for SelfArchiving.

The influence of childhood asthma on puberty and height in Swedish adolescents

Protudjer, Jennifer Lisa; Lundholm, Cecilia; Bergström, Anna; Kull, Inger; Almqvist, Catarina

Access to the published version may require subscription. Published with permission from: Wiley 
Article Type: Original

\section{The influence of childhood asthma on puberty and height in Swedish adolescents}

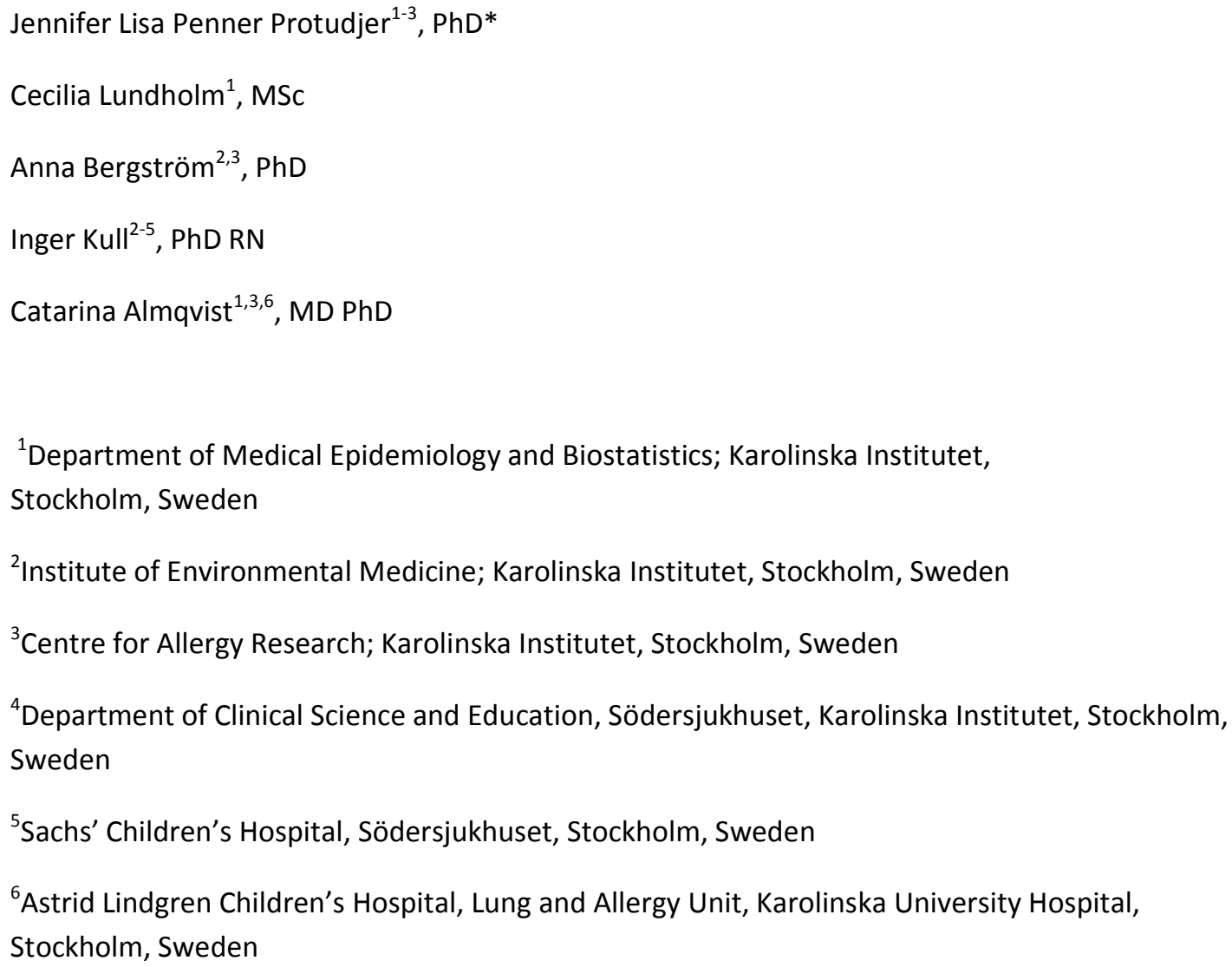

\section{Running Title}

Asthma and puberty in a cohort of Swedish children

\section{*Corresponding author}

Department of Medical Epidemiology and Biostatistics

Karolinska Institutet, Box 281, Stockholm SE-171 77, Sweden

This article has been accepted for publication and undergone full peer review but has not been through the copyediting, typesetting, pagination and proofreading process, which may lead to differences between this version and the Version of Record. Please cite this article as doi: $10.1111 /$ pai.12398

This article is protected by copyright. All rights reserved. 
Phone no: +46 (8) 524824 23; Fax no. +46 (8) 314975

Email: jennifer.protudjer@ki.se

\section{Abstract Page}

Protudjer JLP, Lundholm C, Bergström A, Kull I, Almqvist C. The influence of childhood asthma on puberty and height in Swedish adolescents. Pediatr Allergy Immunol.

Background Evidence relating to the effect of asthma on puberty or height is inconclusive. We aimed to examine if the exposure of childhood asthma, including timing and phenotypes, and inhaled corticosteroid (ICS) use is either cross-sectionally or longitudinally associated with the outcomes of pubertal staging or height.

Methods This study employed data from a longitudinal, population-based cohort of Swedish children (born 1994-1996). At ages 1, 2, 4, 8 and 12 years, parent-reported data on asthma and ICS use in the previous 12 months were collected. At 8 and 12 years, height was ascertained at a clinical visit, and child-reported, respectively. At 12 years, children answered puberty-related questions.

Results Retention through 12 years was 82\% (3366/4089). Participants without puberty data $(n=620)$ were excluded, yielding a study population of $2746(67 \%)$. Asthma at 8 years, including timing of onset and phenotypes were not statistically significantly associated with pubertal staging in adjusted models. Children with asthma averaged $0.93 \mathrm{~cm}(95 \% \mathrm{Cl} 0.35-1.50)$ shorter than children without asthma. Children with asthma using ICS were $1.28(95 \% \mathrm{Cl} 0.62-1.95)$ shorter than those with asthma without using ICS.

Conclusions We found no consistent association between asthma and pubertal staging. Children with asthma were shorter than those without asthma. Moreover, children with asthma using ICS were shorter than those not using ICS.

Key Words: Adolescence, Asthma, BAMSE, Glucocorticoids, Height, Puberty

\section{*Author to whom requests for offprints should be sent}

Department of Medical Epidemiology and Biostatistics

Karolinska Institutet, Box 281, Stockholm SE-171 77, Sweden

Phone no: +46 (8) 524824 23; Fax no. +46 (8) 314975

Email: jennifer.protudjer@ki.se

This article is protected by copyright. All rights reserved. 


\section{INTRODUCTION}

The shift in asthma prevalence and treatment from male to female predominance during the pubertal years (1-4) supports an association between asthma and puberty. The first report on asthma as a predictor of timing of puberty, including pubertal staging, was published four decades ago (5). Yet, as subsequent reports remain collectively inconclusive (5-10), this topic remains of current interest. Amongst boys, some (5), but not all (10) findings support that those with asthma may begin puberty later than those without asthma. Amongst girls, those with asthma may reach menarche (a marker of sexual maturation) at an earlier $(6,9)$ or later $(7)$ age compared to those without asthma. Moreover, inhaled corticosteroids (ICS), the frontline therapy for asthma treatment since the 1970s, may further delay puberty amongst both sexes if given at high daily doses (11).

Notwithstanding the common use of ICS as a treatment for asthma, there is also concern about the effects of ICS on height and growth. In a recently published review, orally inhaled ICS use by pre-pubertal children was found to be associated with short-term delayed growth in some, but not all randomised controlled trials (12). Inconsistent findings may be partly attributable to different treatments, including duration and dosage (12). In the one study with follow-up through adulthood, those who had used ICS in childhood averaged $1.2 \mathrm{~cm}$ shorter than those exposed to a placebo, a difference which was statistically significant, though likely not clinically relevant (13). But, the pubertal years are characterised by substantial physiological changes, including growth (14), thereby mandating an understanding of the associations between ICS and growth during this time. ICS do not appear to be associated with pubertal staging (15). Associations between ICS and height during the pubertal years are collectively inconclusive. For example, some authors have reported that, compared to healthy controls, both asthma and ICS are associated with shorter height $(11,16)$, particularly at doses $>400 \mu \mathrm{g}$ per day (8). In contrast, other authors have not found statistically significant associations between asthma and height, either in the absence of ICS (7) or at low doses (8)..

This article is protected by copyright. All rights reserved. 
In our recently reported cross-sectional findings from a large population-based study, girls in late/post puberty had a reduced odds of early adolescent-onset asthma (17). However, in that study, we did not assess how asthma affects puberty or height. In the present study, we aimed to examine if the exposure of childhood asthma, including timing and phenotypes, and ICS use is either crosssectionally or longitudinally associated with the outcomes of pubertal staging or height.

\section{METHODS}

This study is based on the 'Children, Allergy and Environment in Stockholm: An Epidemiological Study (Swedish acronym: BAMSE)' described in detail elsewhere (18). Swedish-speaking parents of infants born 1994-96 in Stockholm, Sweden were invited to participate. The original cohort $(\mathrm{N}=4089)$ was representative of the study catchment area, other than higher rates of parental smoking amongst non-responders (18).

Parents completed questionnaires when participants were 2 months (baseline) and 1, 2, 4, and 8 years. Participant sex, parental allergy, maternal age or socio-economic status did not differ between participants retained through the 12 year questionnaire and those lost to attrition (19). The 12 year questionnaire was completed by both parents and participants, who ranged in age from 11.4-14.6 years. The response rate through the 12 year questionnaire was $82 \%$ (3366/4089). After excluding participants with missing pubertal staging (detailed below), the response rate for this study was $67 \%$ ( $n=2746 / 4089)$ of the original cohort.

To further enhance questionnaire data, a clinical examination, including blood sampling, was conducted among 2461 participants at 8 years. Sera were analysed for Immunoglobulin E (IgE) to eight common aeroallergens (cat, dog, mites, timothy, birth, mugwort, mould), via Phadiatop ${ }^{\circledR}$ (Thermo Fischer Scientific AB, Uppsala, Sweden).

This article is protected by copyright. All rights reserved. 
Variables

Asthma, including Timing and Phenotypes

Parent-reports of wheeze and ICS use in the 12 months prior to each questionnaire except baseline were used to establish asthma status. In keeping with the BAMSE definition of asthma (20), participants were classified as having asthma based on parent-reports of $\geq 4$ episodes of wheeze or $\geq 1$ episode of wheeze in combination with ICS use in the past 12 months. Although BAMSE uses parent-reports on ICS use, these data have high concordance with dispensing of asthma medications (21). Asthma status was available for $99 \%$ of participants at both 8 years (3397/3431) and 12 years (3339/3366) including all participants at 8 years $(n=2668)$ and 12 years $(n=2721)$ for whom pubertal staging was available. Amongst those with asthma, ICS use in the last 12 months was based on parent-reports at 8 years and 12 years, and was categorised as ICS-treated asthma or non-ICStreated asthma. We also considered asthma timing, defined as follows:

Transient asthma: Asthma at any of the three questionnaires during the first four years $(1,2,4$ years) but not at 8 years.

Persistent asthma: Asthma at any of the three questionnaires during the first four years, and at 8 years.

Late-onset asthma: No asthma at any of the three questionnaires during the first four years, but asthma at 8 years. As our intent with this definition was to capture the association of the timing of asthma onset and subsequent pubertal staging, we restricted the age of onset to 8 years.

Two asthma phenotypes were also considered, based on data from the clinical examination at 8 years. Sensitisation was defined as an IgE level $\geq 0.35 \mathrm{kU} / \mathrm{L}$.

Atopic asthma: Asthma and sensitisation to $\geq 1$ aeroallergens at 8 years.

Non-atopic asthma: Asthma but without sensitisation

This article is protected by copyright. All rights reserved. 
Pubertal Staging, Height and Mean Height Increase

At the 12 year questionnaire, participants completed pubertal development questions (22). Both sexes were queried about pubic hair growth. Boys were also asked about voice change and facial hair growth. Girls were also asked about breast development and menarche. Points were allocated to each variable to create a composite physical development score (22). With the exception of menarche, which was dichotomized as no vs. yes, possible responses for each characteristic above included: not yet started; just started; definitely started; complete/fully developed, with 1-4 points allocated respectively. Points were summed for each participant. From these sums, we generated pubertal staging and a composite pubertal score using the Petersen index (22) and mutually exclusive pubertal staging categories (pre-, early-, mid-, late- or post puberty). For boys, all characteristics contributed equally. Girls reporting menarche by the 12 year questionnaire were categorised as late- or post puberty, regardless of other characteristics. We also considered menarche independent of pubertal staging.

Height was measured at the clinical examination at 8 years. As clinical examinations were not performed at 12 years, we relied on participant-reported height at 12 years. Although measured height is the gold standard, participant-reported height at the ages of our study population approximate measured heights within 0.5-1.5 centimeters (23). Annual mean height increase $(\mathrm{cm})$ was calculated as the absolute difference in height between 8 and 12 years, divided by the age difference between the questionnaires. This denominator was included to lessen the influence of age on height increase, given that participants ranged from 11.4-14.6 years at the 12 year questionnaire.

Confounding Variables

Potential confounding variables were considered using directed acyclic graphs (DAG). Using DAGs generated via DAGitty (24), two potential confounders were identified for the association between

This article is protected by copyright. All rights reserved. 
asthma and pubertal staging (E-Figure 1): Actual age at the 12 year questionnaire, given that age influences pubertal staging and asthma, and BMI z-score at 8 years (25), given the association between high $\mathrm{BMI}$ and pubertal debut (26) and obesity and asthma by the 12 year questionnaire (27). Similarly, these potential confounders were found for the association between asthma and height, with an additional confounder of socio-economic status, based on parent-reported maternal and paternal highest level of education (E-Figure 2).

\section{Statistical Analysis}

Chi-squared test was used to establish if differences existed between the non-responders of the original cohort and our study population. Multinomial logistic regression was used for the trichotomous outcome of pubertal staging. Binomial logistic regression was used to analyse associations between asthma and menarche. Linear mixed models with a random intercept were used for the outcome height and linear regression was used for annual mean height increase. In the mixed model age at height measurement was included and we also tested for interaction between asthma and age/sex, to answer the question if the mean difference between the asthma groups differed by age or sex. Odds ratios (OR) and regression coefficients (i.e. mean difference between exposure groups) with corresponding $95 \%$ confidence intervals $(95 \% \mathrm{Cl})$ are presented as appropriate. The estimated ORs from the logistic models are presented with and without adjustment for age at the 12 year questionnaire. Analyses on asthma status, timing and phenotypes were performed with subgroups using available data. Analyses on ICS use were restricted to children with asthma. Analyses for pubertal staging were stratified by sex, since the categorisation of puberty differed between boys and girls. Statistical significance was set at $p<0.05$. Models for annual mean height increase from between 8 and 12 years of age were not adjusted for age at the 12 year questionnaire, as age was already taken into account in that variable.

This article is protected by copyright. All rights reserved. 
As the potential confounder BMI z-score was ascertained based on the clinical examination at 8 years, it was only available for a subgroup. To evaluate the confounding effect of BMI z-score, we conducted sensitivity analyses on this subgroup. Estimates adjusted only for age at the 12 year questionnaire (outcome: pubertal staging) and for age at the respective times of assessment and socio-economic status (outcome: height) were compared to estimates additionally adjusted for BMI z-score at 8 years.

Permission for this study was obtained from the Regional Ethical Review Board in Stockholm, Sweden. Analyses were performed with STATA 11.0 (StatCorp LP, College Station, TX, USA).

\section{RESULTS}

Amongst our study population ( $\mathrm{n}=2746)$, there was a greater proportion of higher socio-economic status and parental allergy and a larger proportion of infants were exclusively breastfed for a minimum of 4 months compared to the non-responders of the original cohort (E-Table 1). Characteristics of the study population are summarized in Table 1 . Few boys $(31 / 1378 ; 2.2 \%)$ but almost half of girls $(651 / 1368 ; 47.6 \%)$ were in late- or post-puberty. Thus, we created different pubertal staging categories for boys (pre-, early- or mid/late puberty (no boys reported post puberty)) and girls (pre/early-, mid- or late/post puberty). Nearly half of the girls had reached menarche. No children without a parent-report of asthma were reported to use ICS.

Associations between asthma, timing and phenotypes at 8 years, and pubertal staging at 12 years are presented in Table 2 (boys) and Table 3 (girls). The direction of the association between asthma timing and pubertal staging tended to be opposite in boys and in girls. However, in adjusted models, asthma was not associated with pubertal staging in boys or girls, or with menarche.

Atopic asthma was not associated with pubertal staging for boys (mid/late puberty: OR 1.10; $95 \% \mathrm{Cl}$ 0.46-4.64), or girls (late/post puberty: OR $0.35,95 \% \mathrm{Cl} 0.12-1.01$ ).

This article is protected by copyright. All rights reserved. 
Cross-sectional associations, at 8 years and at 12 years, between asthma status, including asthma treatment, and mean height $(95 \% \mathrm{Cl})$ are presented in Figure 1. Children with asthma averaged $0.93 \mathrm{~cm}(95 \% \mathrm{Cl} 0.35-1.50 ; \mathrm{p}=0.002)$ shorter than children without asthma. This did not differ between boys and girls ( $p=0.92)$. There was no difference in the association between 8 and 12 years of age ( $p$ for interaction with age $=0.23$ ). With consideration to current asthma treatment, children with non-ICS-treated asthma averaged $0.06(95 \% \mathrm{Cl}-0.94-1.06) \mathrm{cm}$ shorter and children with ICS-treated asthma averaged $1.28(95 \% \mathrm{Cl} 0.62-1.95) \mathrm{cm}$ shorter than boys without asthma. There were no significant differences between boys and girls with regard to the association between height and ICS-treatment $(p=0.64)$ and no interaction with age $(p=0.33)$.

In Figure 2, we present associations between asthma status, including treatment at 8 years, and mean height $(95 \% \mathrm{Cl})$ at 12 years $($ Panel $A)$ and annual mean height increase $(95 \% \mathrm{Cl})$ from 8 years to 12 years (Panel B). There were no statistically significant differences in height increase by asthma status or ICS treatment.

In the sensitivity analyses of the subgroup which attended the clinical examination at 8 years and for whom pubertal staging were available ( $n=2212 ; 50.5 \%$ boys), adjustment for BMI zscore did not substantially alter the point estimates (absolute difference $<0.10$ ) for any analyses, compared to adjustment only for age at the 12 year questionnaire (outcome: pubertal staging) or for age at the respective times of assessment and socio-economic status (outcome: height).

\section{DISCUSSION}

In this longitudinal, general population birth cohort of Swedish children, asthma at 8 years, including the timing of onset through the first 8 years of life, as well as asthma phenotypes were not associated with pubertal staging at 12 years in either sex, or with menarche. Asthma vs. no asthma was associated with shorter height and there was no statistically significant difference in the association by age or sex. A statistically significant height difference between children with vs.

This article is protected by copyright. All rights reserved. 
without asthma persisted only among those with ICS-treated-asthma, but not those with non-ICStreated asthma. Moreover, children with non-ICS-treated asthma were significantly taller than children with ICS-treated asthma. Our definition of asthma may not have captured disease severity and/or ICS dosage, both of which have been previously reported as influencing height $(5,8,11)$. These observations need to be considered when contextualising our findings.

Differences in study design, ages at assessment and operationalisation of asthma may have contributed to collectively inconclusive results. Despite a long-standing interest in the association between asthma and puberty, there are relatively few reports on this topic $(5,10)$ or the related outcome of menarche $(6,7,9)$ and those which exist are conflicting. But, asthma should not be viewed as a single disease. The timing of asthma onset can be viewed as a proxy for asthma severity (28), with persistent asthma being associated with the most severe disease. As reflected in our study, asthma in early life is often transient. Nonetheless, any asthma-like symptoms in early childhood can impair lung function through the pubertal years (29). However, those who experience persistent asthma throughout childhood will have long-term poorer lung function (28). As we lacked data on lung function at 12 years amongst our study participants, the proxy of timing of onset through 8 years as a marker of asthma severity may not have been an adequately sensitive measure to identify differences in pubertal staging at 12 years. However, it does warrant mention that the point estimates for these associations were in opposite directions for boys and girls. This alone is an interesting observation, and warrants further investigation as our study participants proceed through adolescence.

Consideration to atopic status in relation to asthma is also warranted as another phenotype (28). To our knowledge, only one previous report on atopic asthma in relation to pubertal stages has been published (30). Despite differences in the operationalisation of 'atopic asthma' in our study and elsewhere (30), there is a seemingly consistent association between atopic asthma and later age at menarche.

This article is protected by copyright. All rights reserved. 
Our findings on asthma and ICS use on height are consistent with other studies reporting that children with asthma are shorter in stature than their peers without asthma, a difference which disappears in adulthood (5). We used parent-reported data for ICS use. However, these data have high concordance with dispensed of ICS prescriptions during a 12-month window (the time frame for parent-reports in the present study) (21). Although we lacked data on dosing and severity, our cross-sectional findings parallel a longitudinal study (13) and thus support the theory that both asthma and ICS use may suppress growth in children at 8 and 12 years.

Follow-up, including both questionnaire and clinical data, of BAMSE participants through the 12 year follow-up provides opportunities to create comprehensive definitions of asthma, including phenotypes. Similarly, the use of multiple pubertal characteristics, obtained using a valid instrument (22) permitted the definition of pubertal staging. Both definitions enhance the understanding into the associations between asthma and puberty. Further observation of BAMSE through adolescence and beyond will provide additional opportunities to assess if attained adult height by asthma status.

We acknowledge that our study population consisted of only $67 \%(2746 / 4089)$ of the original cohort, which is a potential weakness of our study. Nonetheless, to our knowledge, this is the largest study on asthma and puberty to date. Moreover, our study population included a higher proportion of children with highly educated parents, parental allergy, and who were more often exclusively breastfed for a minimum of 4 months compared to the non-responders of the original cohort. In addition to largely relying on questionnaire data, we lacked data on asthma severity and dosing or duration of asthma medication use, and could not consider ICS use and pubertal staging or menarche due to small sample sizes.

This article is protected by copyright. All rights reserved. 
In conclusion, we found no consistent association between asthma and pubertal staging.

Children with asthma were shorter than those without asthma, and those with ICS-treated asthma were shorter than those with non-ICS-treated asthma.

\section{Statement of conflicts of interest}

All authors declare that they have no conflicts of interest with regard to this manuscript.

\section{Funding}

The BAMSE study was supported by Stockholm County Council, the Swedish Research Council, the Swedish Council for Working Life and Social Research, the Swedish Heart and Lung Foundation, the Swedish Asthma and Allergy Association's Research Foundation, and the Swedish Foundation for Health Care Science and Allergy Research. Financial support was also provided by grants from Stockholm County Council (ALF project), the Swedish Research Council and the Strategic Research Program in Epidemiology at Karolinska Institutet. JLP Protudjer was first supported by European Respiratory Society Long Term Research Fellowship n ${ }^{\circ} 117-2011$, a Canadian Institutes of Health Research Post-Doctoral Fellowship, and most recently, a post-doctoral researcher funded by the Karen and Sten Mörtstedt Initiative on Anaphylaxis.

Table 1. Characteristics and demographics of BAMSE participants seen through to the 12 year questionnaire and for whom pubertal data were available at the 12 year questionnaire

\begin{tabular}{|c|c|c|c|c|}
\hline \multirow[b]{2}{*}{ Age and pubertal staging } & \multicolumn{2}{|c|}{ Boys } & \multicolumn{2}{|c|}{ Girls } \\
\hline & $\mathrm{n}$ & $\%$ & $\mathrm{n}$ & $\%$ \\
\hline Gender $(n=2746)$ & 1378 & 50.2 & 1368 & 49.8 \\
\hline Age (years) at the 8 year questionnaire $(n=2682)^{*}$ & \multicolumn{2}{|c|}{$8.2 \pm 0.0$} & \multicolumn{2}{|c|}{$8.2 \pm 0.0$} \\
\hline Age (years) at the 12 year questionnaire $(n=2746)^{*}$ & \multicolumn{2}{|c|}{$13.0 \pm 0.8$} & \multicolumn{2}{|c|}{$12.9 \pm 0.8$} \\
\hline \multicolumn{5}{|l|}{ Pubertal Stage at Year $12(n=2746)^{\dagger}$} \\
\hline Pre-puberty & 351 & 25.5 & 53 & 3.9 \\
\hline Early puberty & 599 & 43.5 & 108 & 7.9 \\
\hline
\end{tabular}

This article is protected by copyright. All rights reserved. 


\begin{tabular}{rlcccr}
\hline \hline Mid-puberty & 397 & 28.8 & 556 & 40.6 \\
& Late puberty & 31 & 2.2 & 635 & 46.4 \\
Post-puberty & 0 & 0.0 & 16 & 1.2
\end{tabular}

Menarche $(n=1368)$

\begin{tabular}{rccc} 
No & - & 717 & 52.4 \\
Yes & - & 651 & 47.6 \\
Age at menarche (years; $\mathrm{n}=523$ )* & - & \multicolumn{2}{c}{$12.4 \pm 0.8$}
\end{tabular}

Asthma status

8 year questionnaire $(n=2668)$

$\begin{array}{ccccc}\text { No } & 1240 & 92.7 & 1262 & 94.8 \\ \text { Yes } & 97 & 7.3 & 69 & 5.2\end{array}$

12 year questionnaire $(n=2721)$

$\begin{array}{lcccc}\text { No } & 1251 & 91.6 & 1288 & 95.1 \\ \text { Yes } & 115 & 8.4 & 67 & 4.9\end{array}$

Asthma timing

Asthma timing through the pre-pubertal years $(n=2576)$

$\begin{array}{rcccc}\text { None } & 1077 & 82.8 & 1133 & 88.8 \\ \text { Transient asthma }^{\ddagger} & 127 & 9.8 & 74 & 5.8 \\ \text { Persistent asthma§ }^{*} & 57 & 4.4 & 32 & 2.5 \\ \text { Late-onset asthma }^{* *} & 39 & 3.0 & 37 & 2.9\end{array}$

Asthma phenotype for 2084 children with information on IgE

At Year $8(n=140)$

$\begin{array}{rrrrr}\text { Non-atopic } & 25 & 30.1 & 21 & 36.8 \\ \text { Atopic } & 58 & 69.9 & 36 & 63.2\end{array}$

ICS use amongst those with asthma in the past 12 months

I. 8 year questionnaire $(n=166)^{t+}$

$\begin{array}{rrrrr}\text { Not Used } & 17 & 17.5 & 17 & 24.7 \\ \text { Used } & 80 & 82.5 & 52 & 75.3\end{array}$

This article is protected by copyright. All rights reserved. 
II. 12 year questionnaire $(n=182)$

$\begin{array}{rrrrr}\text { Not Used } & 29 & 25.2 & 26 & 38.8 \\ \text { Used } & 86 & 74.8 & 41 & 61.2\end{array}$

\begin{tabular}{lcc}
\hline $\begin{array}{l}\text { Anthropometry } \\
\text { Measured height }(\mathrm{m}) \text {; 8 year questionnaire }(\mathrm{n}=2212)^{*}\end{array}$ & $1.33 \pm 0.06$ & $1.32 \pm 0.06$ \\
$\begin{array}{l}\text { Child-reported height }(\mathrm{m}) \text {; 12year questionnaire }(\mathrm{n}=2701)^{*} \\
\text { Annual height increase }(\mathrm{cm}) \text { from } 8 \text { years to } 12 \text { years* } \\
(\mathrm{n}=2177)\end{array}$ & $1.60 \pm 0.10$ & $6.07 \pm 0.82$ \\
BMI z-score at 8 years $(\mathrm{n}=2212)^{*} \neq \ddagger$ & $5.97 \pm 1.04$ & $0.4 \pm 0.8$ \\
\hline \hline
\end{tabular}

*mean \pm standard deviation

†As per Petersen et al (22)

${ }^{\ddagger}$ Asthma in the first 4 years (1,2 and/or 4 years), but not at 8 years, based on composite definition from questionnaire data

§Asthma in any of the three surveys during the first four years (1,2 and/or 4 years) and at Year8

${ }^{* *}$ No asthma in any of the three surveys during the first four years (1,2 and/or 4 years), but at 8 years

${ }^{+\dagger}$ Based on those with asthma at the respective year

${ }^{\ddagger \ddagger}$ As per Centres for Disease Control and Prevention (25)

Table 2. Multinomial logistic regression analyses of asthma, including timing and phenotypes, at the 8 year questionnaire and pubertal staging at the 12 year questionnaire, adjusted for age at the 12 year questionnaire, amongst boys participating in BAMSE

\begin{tabular}{|c|c|c|c|c|c|}
\hline \multirow[b]{3}{*}{ Exposures at 8 years } & \multicolumn{5}{|c|}{ Boys' Self-Reported Pubertal Staging at 12 years* } \\
\hline & \multirow[b]{2}{*}{$\mathrm{n}$} & \multicolumn{2}{|c|}{ Early Puberty } & \multicolumn{2}{|c|}{ Mid/Late/Post Puberty } \\
\hline & & OR & $95 \% \mathrm{Cl}$ & OR & $95 \% \mathrm{Cl}$ \\
\hline \multicolumn{6}{|l|}{ Asthma presence vs. absence at 8 years } \\
\hline \multicolumn{6}{|l|}{ Unadjusted } \\
\hline No Asthma & 1240 & 1.00 & & 1.00 & \\
\hline Asthma & 97 & 1.75 & $0.98-3.14$ & 1.77 & $0.96-3.27$ \\
\hline
\end{tabular}

This article is protected by copyright. All rights reserved. 
Adjusted $\dagger$

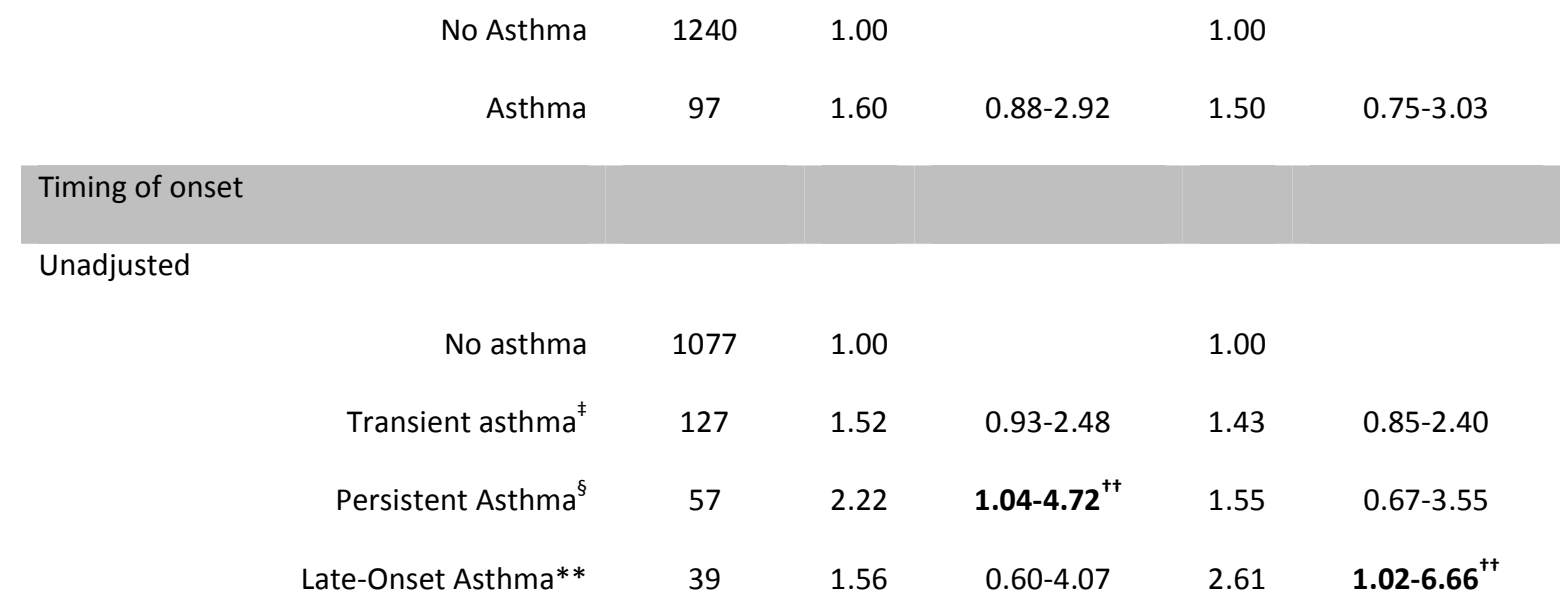

Adjusted $\dagger$

$\begin{array}{rccccc}\text { No asthma } & 1077 & 1.00 & & 1.00 & \\ \text { Transient asthma }^{\ddagger} & 127 & 1.57 & 0.94-2.60 & 1.57 & 0.85-2.90 \\ \text { Persistent Asthma }^{\S} & 57 & 1.87 & 0.86-4.04 & 1.14 & 0.45-2.89 \\ \text { Late-Onset Asthma** }^{*} & 39 & 1.58 & 0.59-4.26 & 2.74 & 0.91-8.21\end{array}$

\section{Asthma, by sensitisation}

Unadjusted

$\begin{array}{rccccc}\text { No asthma } & 649 & 1.00 & & 1.00 & \\ \text { Non-atopic asthma }^{\ddagger \ddagger} & 25 & 2.56 & 0.72-9.09 & 2.73 & 0.73-10.24 \\ \text { Atopic asthma }^{\S \S} & 58 & 1.43 & 0.71-2.87 & 1.29 & 0.60-2.78\end{array}$

Adjusted ${ }^{\dagger}$

$\begin{array}{rccccc}\text { No asthma } & 649 & 1.00 & & 1.00 & \\ \text { Non-atopic asthma }^{\ddagger \ddagger} & 25 & 2.52 & 0.69-9.26 & 2.33 & 0.52-10.53 \\ \text { Atopic asthma }^{\S \S} & 58 & 1.27 & 0.62-2.61 & 1.10 & 0.46-4.64\end{array}$

*Reference group is boys in pre-puberty

${ }^{+}$Adjusted for age at the 12 year questionnaire

${ }^{\ddagger}$ Asthma in the first 4 years (1,2 and/or 4 years), but not at 8 years, based on composite definition from questionnaire data

${ }^{\S}$ Asthma in the first 4 years (1,2 and/or 4 years), and at 8 years, based on composite definition from questionnaire data

This article is protected by copyright. All rights reserved. 
**No asthma in the first 4 years (1,2 and/or 4 years), but asthma at 8 years, based on composite definition from questionnaire data

${ }^{+\dagger} p<0.05$

${ }^{\ddagger \ddagger}$ Asthma at 8 years based on composite definition from questionnaire data, but no sensitisation to common aeroallergens

${ }^{\S}$ Asthma at 8 years based on composite definition form questionnaire data, and sensitisation to $\geq 1$ common aeroallergens

OR Odds ratio

$95 \% \mathrm{Cl} 95^{\text {th }}$ percent confidence interval

Table 3. Multinomial logistic regression analyses of asthma, including timing and phenotypes, at the 8 year questionnaire and pubertal staging at the 12 year questionnaire, adjusted for age at the 12 year questionnaire, amongst girls participating in BAMSE

\begin{tabular}{|c|c|c|c|c|c|c|c|}
\hline \multirow[b]{3}{*}{ Exposures at 8 years } & \multicolumn{7}{|c|}{ Girls' Self-Reported Pubertal Staging at 12 years* } \\
\hline & \multirow[b]{2}{*}{$\mathbf{n}$} & \multirow{2}{*}{$\begin{array}{l}\text { Mid } \\
\text { OR }\end{array}$} & \multirow{2}{*}{$\begin{array}{l}\text { Puberty } \\
95 \% \mathrm{Cl}\end{array}$} & \multicolumn{2}{|c|}{ Late/Post Puberty } & \multicolumn{2}{|c|}{ Menarche } \\
\hline & & & & OR & $95 \% \mathrm{Cl}$ & OR & $95 \% \mathrm{Cl}$ \\
\hline \multicolumn{8}{|l|}{ Asthma presence vs. absence at 8 years } \\
\hline \multicolumn{8}{|l|}{ Unadjusted } \\
\hline No Asthma & 1262 & 1.00 & & 1.00 & & 1.00 & \\
\hline Asthma & 69 & 0.75 & $0.36-1.59$ & 0.78 & $0.37-1.62$ & 0.96 & $0.59-1.57$ \\
\hline \multicolumn{8}{|l|}{ Adjusted $\dagger$} \\
\hline No Asthma & 1262 & 1.00 & & 1.00 & & 1.00 & \\
\hline Asthma & 69 & 0.69 & $0.32-1.48$ & 0.67 & $0.30-1.52$ & 0.92 & $0.54-1.58$ \\
\hline \multicolumn{8}{|l|}{ Timing of onset } \\
\hline \multicolumn{8}{|l|}{ Unadjusted } \\
\hline No asthma & 1133 & 1.00 & & 1.00 & & 1.00 & \\
\hline Transient asthma ${ }^{\ddagger}$ & 74 & 0.95 & $0.44-2.05$ & 0.92 & $0.43-1.97$ & 0.96 & $0.60-1.54$ \\
\hline Persistent Asthma & 32 & 1.04 & $0.34-3.17$ & 0.79 & $0.25-2.48$ & 0.77 & $0.38-1.58$ \\
\hline
\end{tabular}

This article is protected by copyright. All rights reserved. 


$\begin{array}{llllllll}\text { Late-Onset Asthma** } & 37 & 0.55 & 0.20-1.50 & 0.77 & 0.30-1.98 & 1.19 & 0.62-2.30\end{array}$

Adjusted +

\begin{tabular}{|c|c|c|c|c|c|c|c|}
\hline No asthma & 1133 & 1.00 & & 1.00 & & 1.00 & \\
\hline Transient asthma $^{\ddagger}$ & 74 & 0.85 & $0.39-1.86$ & 0.78 & $0.34-1.78$ & 0.89 & $0.52-1.51$ \\
\hline Persistent Asthma ${ }^{\S}$ & 32 & 0.93 & $0.30-2.94$ & 0.65 & $0.19-2.27$ & 0.69 & $0.31-1.52$ \\
\hline ate-Onset Asthma** & 37 & 0.50 & 0.18-1.39 & 0.67 & $0.24-1.93$ & 1.17 & $0.57-2.42$ \\
\hline
\end{tabular}

\section{Asthma, by sensitisation}

Unadjusted

\begin{tabular}{|c|c|c|c|c|c|c|c|}
\hline No asthma & 672 & 1.00 & & 1.00 & & 1.00 & \\
\hline Non-atopic asthma + & 21 & 1.02 & $0.21-4.93$ & 1.24 & $0.27-5.72$ & 1.22 & $0.51-2.90$ \\
\hline Atopic asthma $\ddagger$ & 36 & 0.55 & $0.22-1.40$ & 0.45 & $0.18-1.16$ & 0.70 & $0.35-1.40$ \\
\hline
\end{tabular}

Adjusted ${ }^{\dagger}$

\begin{tabular}{|c|c|c|c|c|c|c|c|}
\hline No asthma & 672 & 1.00 & & 1.00 & & 1.00 & \\
\hline Non-atopic asthma†† & 21 & 0.97 & $0.20-4.76$ & 1.17 & $0.22-6.24$ & 1.21 & $0.45-3.27$ \\
\hline Atopic asthmał & 36 & 0.47 & $0.18-1.23$ & 0.35 & $0.12-1.01$ & 0.64 & $0.30-1.38$ \\
\hline
\end{tabular}

*Reference groups are girls in pre/early puberty, and non-menarchal girls, respectively

${ }^{\dagger}$ Adjusted for age at the 12 year questionnaire

${ }^{\ddagger}$ Asthma in the first 4 years (1,2 and/or 4 years), but not at 8 years, based on composite definition from questionnaire data

${ }^{\S}$ Asthma in the first 4 years (1,2 and/or 4 years), and at 8 years, based on composite definition from questionnaire data

**No asthma in the first 4 years (1,2 and/or 4 years), but asthma at 8 years, based on composite definition from questionnaire data

††Asthma at 8 years based on composite definition from questionnaire data, but no sensitisation to common aeroallergens

$\ddagger \ddagger A s t h m a$ at 8 years based on composite definition form questionnaire data, and sensitisation to $\geq 1$ common aeroallergens

OR Odds ratio

$95 \% \mathrm{Cl} 95^{\text {th }}$ percent confidence interval

Figure 1. Cross-sectional associations of asthma status and treatment as exposures and mean height $(\mathrm{cm})$ adjusted for age at the respective times of assessment and for socio-economic status, amongst BAMSE participants

This article is protected by copyright. All rights reserved. 


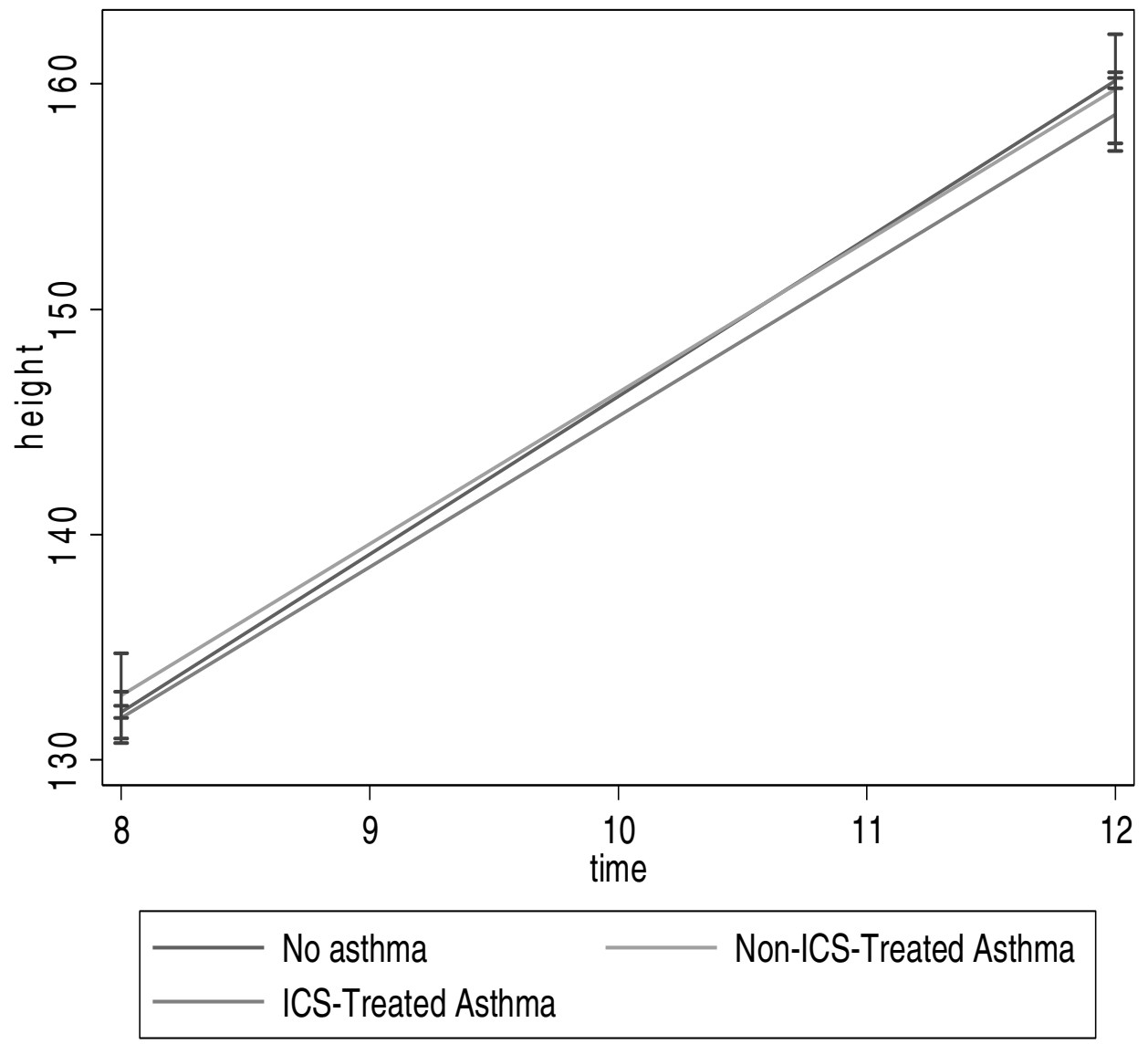

ICS: Inhaled corticosteroids

This article is protected by copyright. All rights reserved. 
Figure 2. Associations of asthma status and treatment, at 8 years, as exposures and height $(\mathrm{cm})$ at 12 years (Panel $A$ ) and annual mean height increase from 8 years to 12 years (Panel B) with $95 \%$ confidence intervals, as outcomes, as estimated by linear regression analysis, adjusted for age at the respective times of assessment and for socio-economic status, for boys and girls

Panel A. Associations between asthma status and treatment at 8 years and mean height $(\mathrm{cm})$ at 12 years with $95 \%$ confidence intervals

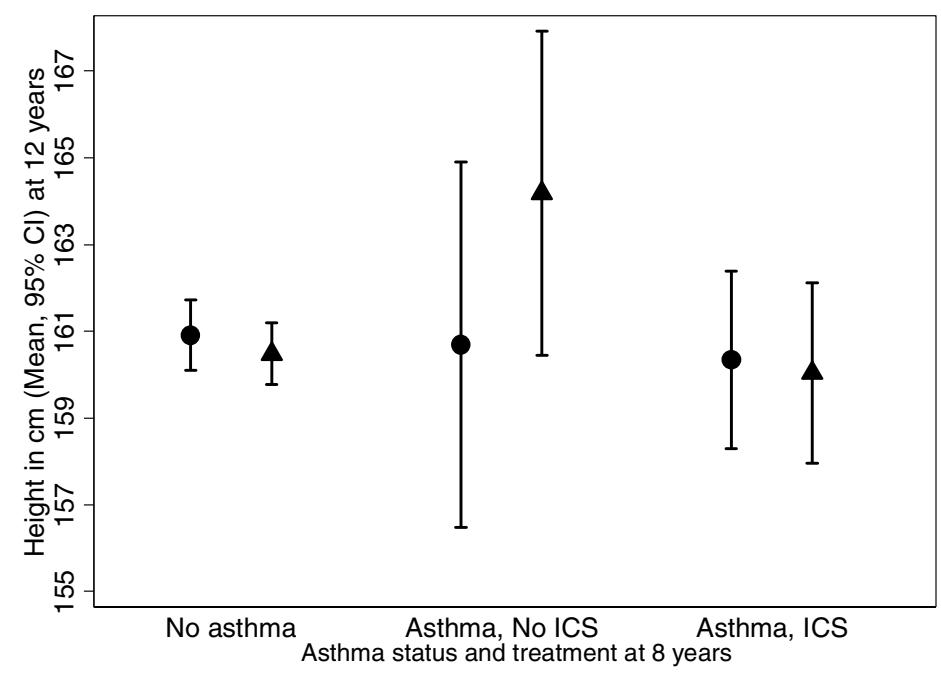

Panel B. Associations between asthma status and treatment at 8 years and annual mean height increase from 8 years to 12 years $(\mathrm{cm})$ with $95 \%$ confidence intervals

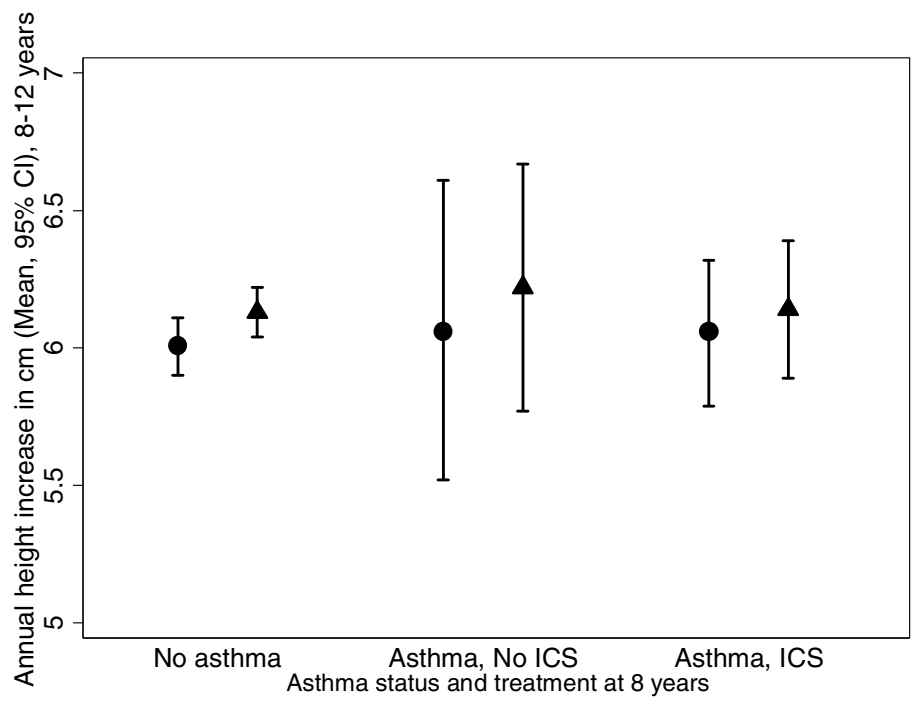

Circles: Boys; Triangles: Girls

This article is protected by copyright. All rights reserved. 


\section{References}

1. Almqvist CA, Worm M, Leynaert B. Impact of gender on asthma in childhood and adolescence: a GA2LEN review. Allergy. 2008 Jan;63(1):47-57.

2. Postma DS. Gender differenecs in asthma development and progression. Gend Med. 2007;4(Suppl B):S133-46.

3. Mandhane P, Greene JM, Cowan JO, Taylor R, Sears MR. Sex differences in factors associated with childhood- and adolescent-onset wheeze. Am J Respir Crit Care Med. 2005;172:45-54.

4. Lawson JA, Janssen I, Bruner MW, Hossain A, Pickett W. Asthma incidence and risk factors in a national longitudinal sample of adolescent Canadians: a prospective cohort study. BMC Pulm Med. 2014 Mar;14.

5. Hauspie R, Susanne C, Alexander F. Maturational delay and temporal growth retardation in asthmatic boys. J Allergy Clin Immunol. 1977;59(3):200-6.

6. Drosdzol A, Wilk K, Nowosielski K. The influence of bronchial asthma on sexual maturation of girls. J Physiol Pharmacol. 2007;1:155-63.

7. Moudiou T, Theophilatou D, Prifits K, Papadimitriou A. Growth of asthmatic children before long-term treatment with inhaled corticosteroids. J Asthma. 2003 Sep;40(6):667-71.

8. Neville RG, McCowan C, Thomas G, Crombie IK. Asthma and growth - cause for concern? Asthma \& Growth in Tayside Children. Ann Hum Biol. 1996 Jul-Aug;23(4):323-31.

9. Skrzypuklec V, Doniec Z, Drosdzol A, Nowosielski K, Pawlinska-Chmara R. The influence of bronchial asthma on premenstrual syndrome prevalence amongst girls. J Physiol Pharmacol. 2007 Nov;58(Suppl 5):639-46.

10. Vink N M, Postma D S, Schouten J P, et al. Gender differences in asthma development and remission during transition through puberty: the TRacking Adolescents' Individual Lives Survey (TRAILS) study. J Allergy Clin Immunol. 2010;126(3):498-504.

11. El-Sayed Z A, Hamza R T, Sayed N-D, Mahmoud N H. Effect of inhaled corticosteroids on growth and puberty in Egyptian asthmatic children and adolescents. Pak J Biol Sci. 2010;13(20):97784.

12. Hoover RM, Erramouspe J, Bell EA, Cleveland KW. Effect of inhaled corticosteroids on longterm grown in pediatric patients with asthma and allergic rhinitis. Ann Pharmacother. 2013 Sep;47(9).

13. Kelly HW, Sternberg AL, Lescher R, Fuhlbrigge AL, Williams P, Zeiger RS, et al. Effect of inhaled corticosteroids in childhood on adult height. N Engl J Med. 2012 Sep;367(10):904-12.

14. Status. WECoP. Physical status: the use and interpretation of anthropometry1995: Available from: http://whqlibdoc.who.int/trs/WHO_TRS_854.pdf.

This article is protected by copyright. All rights reserved. 
15. The Childhood Asthma Management Program Research Group. Long term effects of budesonide or nedocromil in children with asthma. N Engl J Med. 2000;343:1054-63.

16. Umlawska W, Gaszczyk G, Sands D. Physical development in children and adolescents with bronchial asthma. Respir Physiol Neurobiol. 2013 Jun;187(1):108-13.

17. Protudjer JLP, Lundholm C, Bergstrom A, Kull I, Almqvist C. Puberty and asthma in a cohort of Swedish children. Annals of allergy, asthma \& immunology : official publication of the American College of Allergy, Asthma, \& Immunology. 2014 Jan;112(1):78-9.

18. Wickman M, Kull I, Pershagen G, Nordvall S L. The BAMSE Project: presentation of a prospective longitudinal birth cohort study. Pediatr Pulmonol. 2002;13(suppl 15):11-3.

19. Ballardini N, Kull I, Lind T, Hallner E, Almqvist C, Östblom E, et al. Development and comorbidity of eczema, asthma and rhinitis to age 12 - data from the BAMSE birth cohort. Allergy. 2012 Apr;67(4):534-44.

20. Wickman M, Melen E, Berglind N, Lennart Nordvall S, Almqvist C, Kull I, et al. Strategies for preventing wheezing and asthma in small children. Allergy. 2003;58(8):742-7.

21. Dahlen E, Almqvist C, Bergström A, Wettermark B, Kull I. Concordance between parentalreported use and dispensed asthma drugs in adolescents: findings from the BAMSE birth cohort. Clin Exp Allergy. 2014.

22. Petersen AC, Crockett L, Richards M, Boxer A. A self-report measure of pubertal status: reliability, validity, and initial norms. J Youth Adolesc. 1988 Apr;17(2):117-33.

23. Brettschneider A-K, Schaffrath Rosario A, Ellert U. Validity and predictors of BMI dervied from self-reported height and weight among 11- to 17-year-old German adolescents in the KiGGS study. BMC Res Notes. 2011;4.

24. Textor J, Hardt J, Knuppel S. DAGitty: a graphical tool for analyzing causal diagrams. Epidemiology. 2011;5(22):745.

25. Prevention. CfDCa. A SAS program for the CDC growth charts 2011 [2011 June 27]; Available from: http://www.cdc.gov/nccdphp/dnpao/growthcharts/resources/sas.htm.

26. Lewitt MS, Baker JD, Mooney GP, Thomas NE. Pubertal stage and measures of adiposity in British schoolchildren. Ann Hum Biol. 2012 Sep;39(5):440-7.

27. Holguin F, Bleecker ER, Busse WW, Calhoun WJ, Castro M, Erzurum SC, et al. Obesity and asthma: an association modified by age on asthma onset. J Allergy Clin Immunol. 2011 Jun;127(6):1486-93.e.2.

28. Hancox RJ, Subbarao P, MR S. Relevance of birth cohorts to assessment of asthma persistence. Curr Allergy Asthma Rep. 2012 Jun;12(3):175-84.

29. Morgan WJ, Stern DA, Sherrill DL, Guerra S, Holberg CJ, Guilbert TW, et al. Outcome of asthma and wheezing in the first 6 years of life: follow-up through adolescence. Am J Respir Crit Care Med. 2005 Nov;172(10):1253-8.

This article is protected by copyright. All rights reserved. 
30. Galobardes B, Patel S, Henderson J, Jeffreys M, Davey Smith G. The association between irregular menstruations and acne with asthma and atopy phenotypes. Am J Epidemiol. 2012 Sep;176(8):733-7.
Abbreviations:
BAMSE Barn allergi miljö Stockholm Epidemiologi Projektet (Children, Allergy and Environment in Stockholm: An Epidemiological Study)
DAG Directed acyclic graph
ICS Inhaled corticosteroid
IgE Immunoglobulin E
OR Odds ratio
$95 \% \mathrm{Cl} \quad 95 \%$ confidence interval

This article is protected by copyright. All rights reserved. 